\title{
Human Hair as Fiber Reinforced Concrete for Enhancement of Tensile Strength of Concrete
}

\author{
HUMMAIRA KANWAL*, MUHAMMAD SHAHZAD ASLAM*, TAYYABA LATIF MUGHAL***, \\ MUHAMMAD ASIM*, AND REENA MAJID MEMON**
}

RECEIVED ON 08.08.2018, ACCEPTED ON 31.04.2019

\begin{abstract}
FRC (Fibre Reinforced Concrete) is fibrous material which increases its structural integrity, resists explosive spalling in case of environmental affects, improves mix cohesion, improves ductility, reduces steel reinforcement requirements and reduces the voids due to good stiffness. It contains short discrete fibres that are uniformly distributed. Mostly, natural fibers are the waste material which may have negative impact on environment. Synthetic fibres include steel fibres and glass fibres but natural fibres are coconut fibres and human hair fibres which tend to vary the properties to concrete. In addition, the character of FRC changes with varying concrete, fibre material, geometries, distribution, orientation and densities. Hair fibre concrete gives a practical, cost-effective and convenient method to avoid cracks and deficiencies regarding strength and proper mixing ratio which occurs at a longer period. Fibres have been used to reduce plastic shrinkage and drying shrinkage in concrete. In some structural elements, fibrous concrete can be used to reduce the cost of structure. Different fibres are used to improve the tensile strength of concrete. Human hair are strong in tension. Hair fibres can be utilized as a strengthening material. Hair fibre is a non decayable matter and available at a cheap rate. Experiments have been performed on fibrous concrete cylinders containing various percentages of human hair which is $0,0.5,1$ and $1.5 \%$ by the weight of cement. A total of seventy-two cylinders have been prepared with FRC having different \%ages of hair content. Workability, compressive strength and split tensile strength have been checked at three curing ages i.e. 7, 14 and 28 days. This research will open a new wicket in the horizon of reuse of waste material efficiently in construction industry. This innovation in construction industry will save our natural resources and use fibre in productive and an effective approach.
\end{abstract}

Key Words: Fibre Reinforced Concrete, Human Hair, Workability, Compressive Strength, Tensile Strength.

\section{INTRODUCTION}

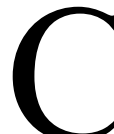

oncrete is the most commonly used construction material which is the backbone of construction [1]. It has little resistance to cracking. All structural industry. It has low tensile strength and ductility members of building have been made by this like foundations, beams, slabs, columns and roofs [2]. By

Authors E-Mail: (hmugha184@gmail.com, engr.hafizshahzad03@gmail.com, drtayyabamughal88@gmail.com, asimashraf203@gmail.com, reenamemon09@gmail.com)

* Department of Civil Technology,The University of Lahore, Lahore, Pakistan.

** Department of Architecture \& Planning, Dawood University of Engineering \& Technology, Karachi, Pakistan.

*** $\quad$ Fatima Jinnah Medical College, Lahore

This is an open access article published by Mehran University Research Journal of Engineering and Technology, Jamshoro under the CC by 4.0 International License. 
adding fiber in concrete, properties of concrete can either be increased or decreased like compressive strength and tensile strength[3-4]. Concrete is fibrous material and addition of any kind of fibre in powder form or very small pieces will give the better results in wet areas where environmental effects deteriorate the buildings [5-6].

Fibre is a small piece of reinforcing material possessing certain properties. Addition of hair fibre to concrete affects the mechanical properties of concrete which depends on the percentage, length and type of fibre [7]. A good fibre must be compatible with binder. However, hair fibres are added in concrete to increase the mechanical properties of concrete[8-9]. Voids are left even after proper mixing of ordinary concrete. To overcome this issue fibres are used to fill the voids and reduced impact of cracking. Presence of fibrous material in concrete can enhance the durability of structure [1011].

In our country, different catagories of human hair are present in different regions may be due to the environmental change as a waste material[12]. Thickness and stiffness can vary from person to person. It creates a lot of environmental issues and disturbs our sewerage system too [13-14].This is creating a negative impact on the environment [15-16]. The main objective of this study is to explore the possibility to use human hair as fibrous material to improve the mechanical characteristics of concrete.

\section{METHODOLOGY}

\subsection{Collection of Raw Material}

Materials used in this study are:

- $\quad$ OPC (Ordinary Portland Cement):53 grade cement
- Human Hair Fibre: Human hair fibers have been collected from salons and parlours of WAPDA Town which are shown in Fig. 1.

- Treatment has been done by the use of acetone to clean hair fibre.

- Water: Fresh tap water of concrete lab (The University of Lahore).

- $\quad$ Fine aggregate: Locally available sand passing through $4.75 \mathrm{~mm}$ sieve size.

- $\quad$ Coarse aggregate: Margallah crush (aggregate size is $20 \mathrm{~mm}$ down).

\subsection{Mix Design}

Concrete strength $25 \mathrm{MPa}$ (4000 Psi) have been assumed. Concrete mixing ratios for all mixes are 1:2:4 and water cement ratios are $0.6[2,11]$.

\subsection{Mixing Detail}

Four types of mixes (M1, M2, M3 and M4) with different percentages of human hair fibre have been used in this research.

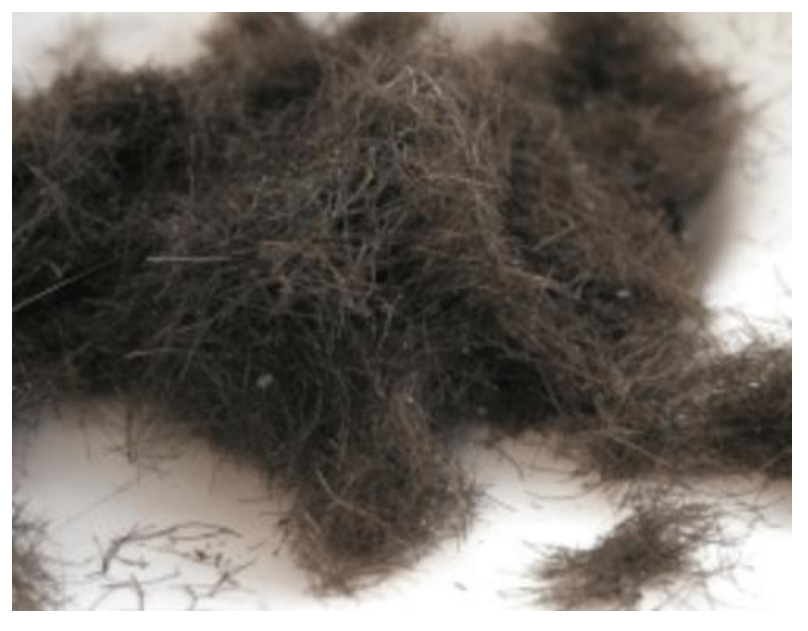

FIG. 1. SAMPLE OF HUMAN HAIR FIBRE 
- $\quad \mathrm{M} 1=$ Hair Fibre $(0 \%)$ and coarse aggregate (Margallah)

- $\quad \mathrm{M} 2=$ Hair Fibre $(0.5 \%)$ and coarse aggregate (Margallah)

- $\quad \mathrm{M} 3=$ Hair Fibre (1.0\%) and coarse aggregate (Margallah)

- $\quad \mathrm{M} 4=$ Hair Fibre $(1.5 \%)$ and coarse aggregate (Margallah)

\section{$2.4 \quad$ Workability}

Workability of these M1, M2, M3 and M4 mixes are measured using the slump test (ASTM C 143).

\subsection{Casting}

Casting of cylinders have been done after measuring the workability of concrete. Seventy-two cylinders in total (Nine cylinders for each type of hair fibre percentage) were casted in accordance with the (ASTM C-192), to test the cylinders at different ages (7, 14 and 28). The detail of the cylinders is given in Table 1.

\subsection{Curing}

Casted cylinders have been immersed in normal fresh water for curing. Three curing ages (7, 14 and 28 days) have been selected for four types of mixes (M1,M2,M3 and M4).

\section{EXPERIMENTAL WORK}

\subsection{Treatment of Hair Fibre}

Treatment of hair fibres are required before the mixing of concrete samples. Some steps have been followed.
- $\quad$ Separating: Hair fibres have been collected from salons which may contain solid wastes depending upon the source. It has been taken off.

- Washing: After categorization, hair fibres are washed with acetone to remove impurities.

- Drying: The hair is dried under sun or oven. After drying, the hair can be stored.

\section{$3.2 \quad$ Tests}

Following tests are performed to check the mechanical characteristics of all mixes.

- $\quad$ Slump Test

- $\quad$ Compression Test

- $\quad$ Split Tensile Test

\subsection{Workability of Concrete}

Workability is the ease by which concrete has been mixed, transported, molded and compacted. The usual range of workability is taken as $40-60 \mathrm{~mm}$ for the use in foundations, slabs, beams and columns etc. Workability has been measured using ASTM C 143 and shown in Fig. 2.

\subsection{Compressive Strength of Concrete}

Compressive strength has been measured by testing of concrete cylinders at room temperature under control compression testing machine as per ASTM C 39. Cylinders were taken out from curing tank at the

TABLE 1. NUMBER OF CYLINDERS CASTED

\begin{tabular}{|c|c|c|c|c|c|}
\hline \multirow{2}{*}{ Description } & Days & $0.0 \%(\mathrm{M} 1)$ & $0.5 \%(\mathrm{M} 2)$ & $1.0 \%(\mathrm{M} 3)$ & $1.5 \%(\mathrm{M} 4)$ \\
\hline \multirow{3}{*}{72 Cylinders } & 7 & & $3+3$ & $3+3$ & $3+3$ \\
\cline { 2 - 4 } & 14 & $3+3$ & & & \\
\hline
\end{tabular}

Mehran University Research Journal of Engineering \& Technology, Volume 39, No. 1, January, 2020 [p-ISSN: 0254-7821, e-ISSN: 2413-7219] 
respective days, wiped off and kept at room temperature for 2 hours. Then cylinders were caped with plaster of paris which is shown in Fig. 3. Caped cylinders were placed in the control compression testing machine which is shown in Figs. 4-5. Load was applied at a constant rate $2.5 \mathrm{MPa} / \mathrm{min}$ up to the ultimate (crushing) strength. Similarly, all the cylinders were tested at the corresponding ages.

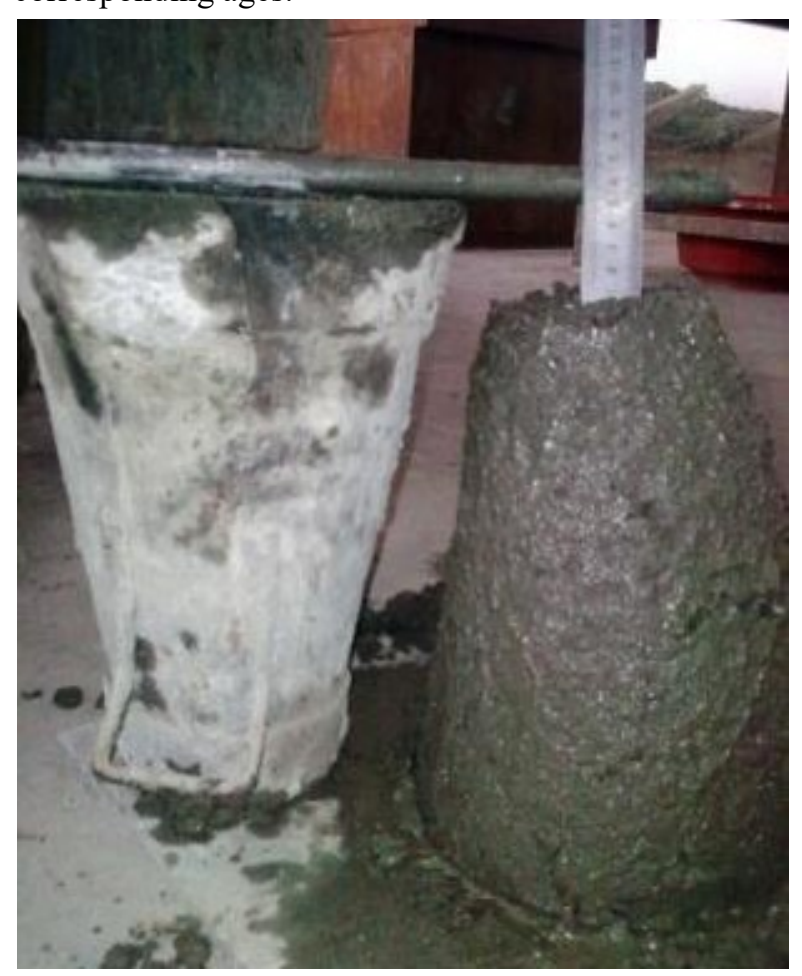

FIG. 2. MEASURING THE WORKABILITY OF CONCRETE (UOL $L A B)$

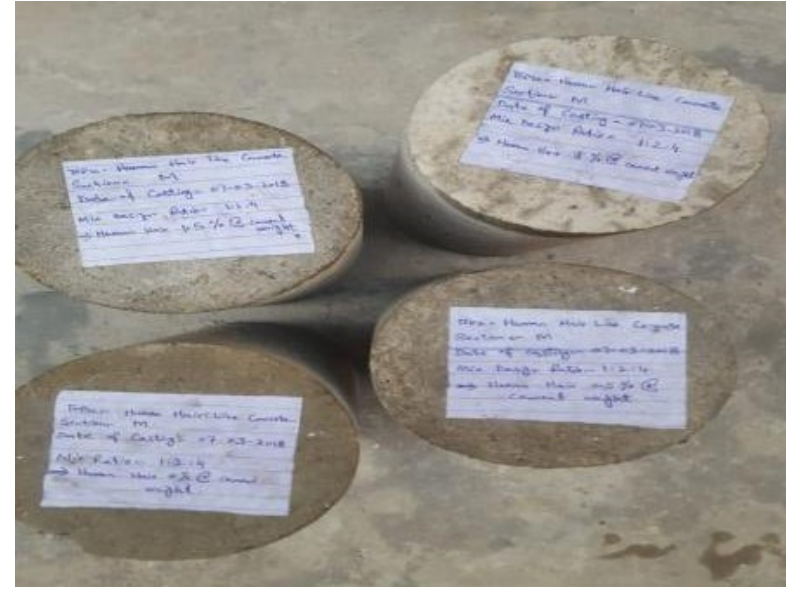

FIG. 4. CONCRETE CYLINDERS READY FOR TESTING (UOL $L A B)$

\subsection{Split Tensile Strength of Concrete}

Split Tensile strength tests have been performed for the cylinders of $150 \mathrm{~mm}$ diameter and $300 \mathrm{~mm}$ length at different curing ages are specified as above 2.4.

\section{RESULTS AND DISCUSSION}

\subsection{Workability}

Results are tabulated on each type of mix as shown in below Table 2. Workability of all mixes are within the acceptable range.

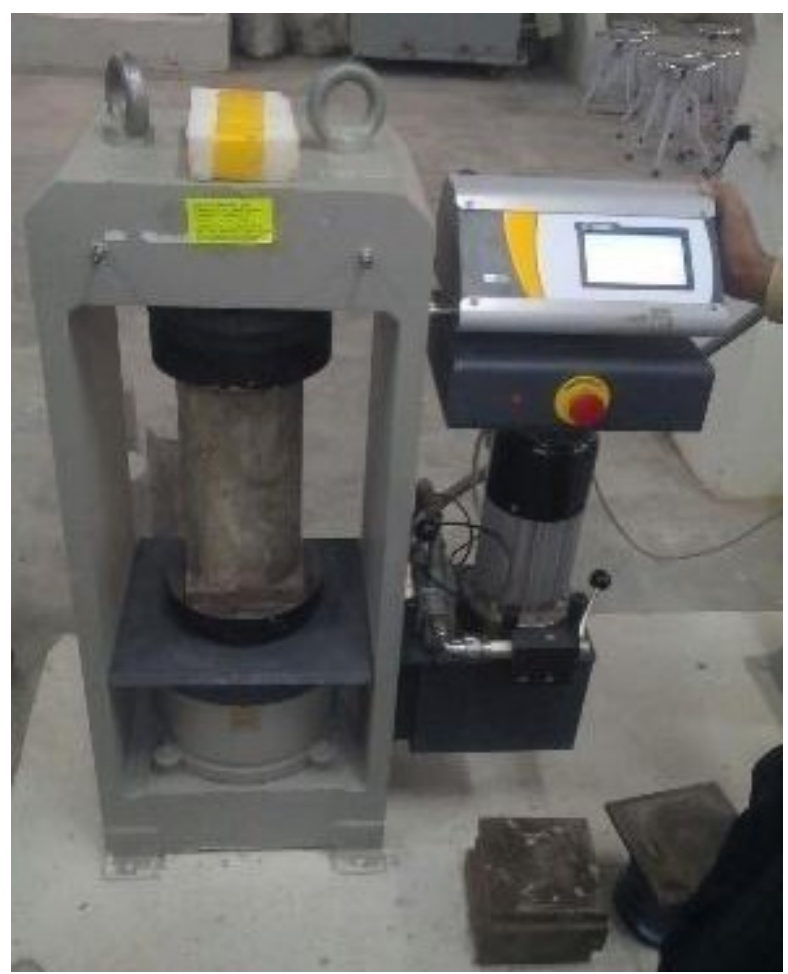

FIG. 5. COMPRESSION TESTING MACHINE (UOL LAB)

TABLE 2. RESULTS OF SLUMP TEST (AUTHOR)

\begin{tabular}{|c|c|c|}
\hline No. & Description & Slump Value (mm) \\
\hline 1. & M1 & 50 \\
\hline 2. & M2 & 60 \\
\hline 3. & M3 & 55 \\
\hline 4. & M4 & 40 \\
\hline
\end{tabular}

Mehran University Research Journal of Engineering \& Technology, Volume 39, No. 1, January, 2020 [p-ISSN: 0254-7821, e-ISSN: 2413-7219] 
Workability of concrete for M1, M2, M3 and M4 mixes are shown in Fig. 6 which is between $40-60 \mathrm{~mm}$.

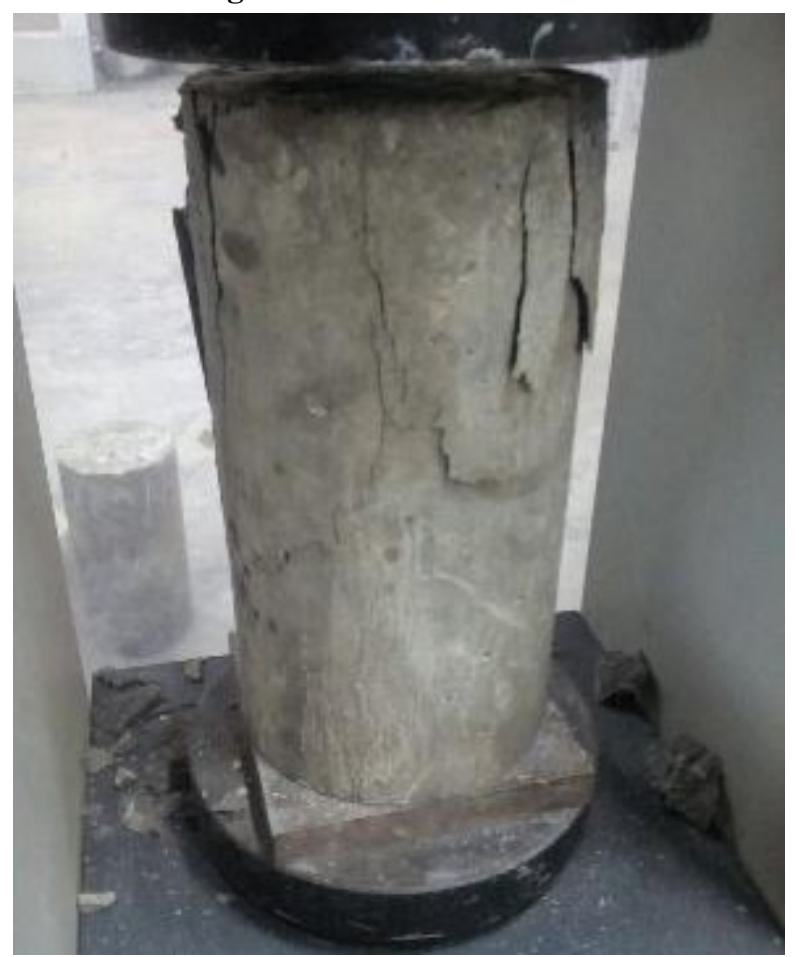

FIG. 6. CRUSHING FAILURE (UOL LAB)

\subsection{Compressive Strength}

Compressive strengths are calculated by taking average of three tested samples for each type of mix at different ages. The results of compressive strength are shown in below Table 3 and graph has been plotted in Fig. 7.

Compressive Strength of concrete mix M1, M2, M3 and M4 are shown in Fig. 8 at the age specified in as above 4.2 .

\subsection{Split Tensile Strength}

Tensile strengths are calculated by taking average of three tested samples for each type of mix at different ages. The results of tensile strength are shown in below Table 4 and graphs have been plotted in Fig. 8 .

\section{CONCLUSION}

The following conclusions have been drawn from the experimental results.

TABLE 3. RESULTS OF COMPRESSIVE STRENGTH

\begin{tabular}{|c|c|c|c|c|c|}
\hline \multirow{2}{*}{ No. } & \multirow{2}{*}{ Number of days } & \multicolumn{4}{|c|}{ Compressive Strength (MPa) } \\
\cline { 3 - 6 } & & M1 & M2 & M3 & M4 \\
\hline 1. & 7 & 12.42 & 12.64 & 13.12 & 13.46 \\
\hline 2. & 14 & 16.38 & 15.90 & 16.88 & 17.42 \\
\hline 3. & 28 & 24.35 & 24.08 & 25.34 & 25.63 \\
\hline
\end{tabular}

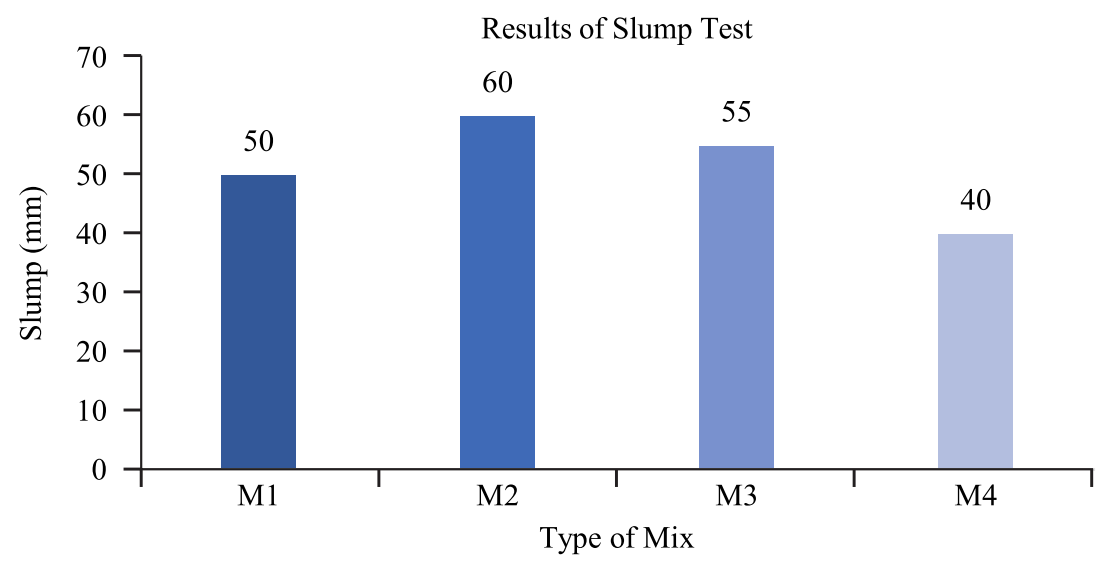

FIG. 6. SLUMP OF M1, M2, M3 AND M4 (AUTHOR) 
(i) Workability of the concrete made with Human hair of different percentage $(0,0.5,1$ and $1.5 \%)$ lies between $40-70 \mathrm{~mm}$, which is adequate for normal use of concrete. The workability of concrete with $0.5 \%$ of human hair is highest and for concrete with $1.5 \%$ human hair is lower. (ii)

Compressive Strength (fc') of all the mixes increased with age. The strength of concrete (M4) made with $1.5 \%$ of human hair is higher than concrete (M2) made with $0.5 \%$ and concrete (M3) made with by using $1.0 \%$.It shows that human hair as a fiber can be used to achieve the strength more than normal concrete.

TABLE 4. RESULTS OF SPLIT TENSILE STRENGTH

\begin{tabular}{|c|c|c|c|c|c|}
\hline \multirow{2}{*}{ No. } & \multirow{2}{*}{ Number of days } & \multicolumn{4}{|c|}{ Split Tensile Strength (N/mm $\left.{ }^{2}\right)$} \\
\cline { 3 - 6 } & & M1 & M2 & M3 & M4 \\
\hline 1. & 7 & 2.26 & 2.40 & 2.48 & 2.60 \\
\hline 2. & 14 & 2.61 & 2.72 & 2.88 & 2.98 \\
\hline 4. & 28 & 3.1 & 3.28 & 3.44 & 3.54 \\
\hline
\end{tabular}

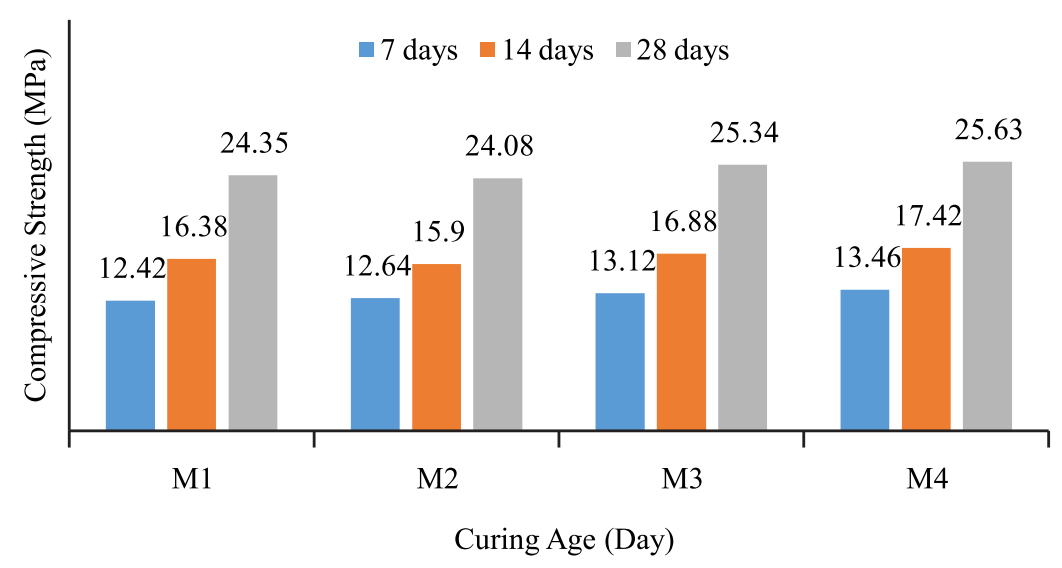

FIG. 7. COMPARISON OF COMPRESSIVE STRENGTH OF DIFFERENT MIXES

$$
\square 7 \text { days } \square 14 \text { days } \square 28 \text { days }
$$

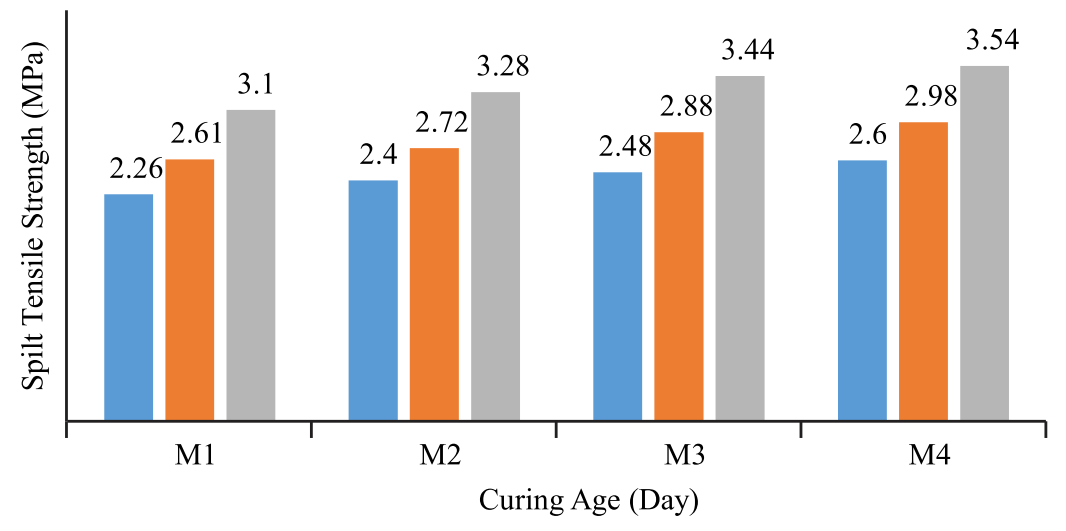

FIG. 8. COMPARISON OF SPLIT TENSILE STRENGTH OF M1, M2, M3 AND M4 AT 7,14 AND 28 DAYS (AUTHOR) 
(iii) Maximum compressive strength is achieved at $1.5 \%$ of human hair which is $5 \%$ of the normal concrete.

(iv) Split Tensile Strength (fc') of all the mixes increased by adding different percentages of human hair. The strength of concrete (M4) made with $1.5 \%$ of human hair is higher than the concrete (M3 and M2) made with $1.0 \%$ and $0.5 \%$ respectively.

(v) As the strength of M4 is highest so treated human hair can be used for mixing and curing of concrete.

(vi) Fibrous concrete increases the binding properties and reduces the voids resultantly cracks in concrete.

\section{ACKNOWLEDGEMENT}

The authors gratefully acknowledge the assistance provided by The University of Lahore, Lahore, Pakistan. Authors also thankful staff of concrete laboratory of The University of Lahore, who provide us assistance to complete our research.

\section{REFERENCES}

Correal, J.F., Herran, C.A., Carrillo, J., Reyes, J.C., and Hermida, G., "Performance of Hybrid Fibre Reinforced Concrete for Low Rise Housing with Thin Walls", Journal of Construction and Building Materials, Volume 185, No. 2, pp. 519-529, 2018.

[2] Antonio, M., and Giuseppe, T., "The Effect of Fibre Orientation on the Post Cracking Behavior of Steel Fiber Reinforced Concrete under Bending and Uniaxial Tensile Tests", Cement and Concrete Composites, Volume 93, No. 3, pp. 274-288, 2018.
[3] Manaf, A., Arshad, M.V., Jomichan, A., and Varghese M.G., "Human Hair Fibre Reinforced Concrete", International Journal ofEngineering Research \& Technology, Volume 6, No. 3,pp. 460-465, 2017.

[4] Yang, Y., and Yang, W., "Structure and Mechanical Behavior of Human Hair", Material Science and Engineering, Volume 73, pp. 152-163, April, 2017.

[5] Sreevani, G., and Ajitha, B.S., "Human Hair as Fibre Reinforcement in Concrete", International Journal of Engineering Science and Computing, Volume 7, No. 5, pp. 11358-11364, 2017.

[6] Mani, K., and Manisundar, A., "Study on Concrete with Human Hair Fibre Reinforced Concrete", Article ID ICACIEM 119 eAID ICACIEM, 2017.

[7] Agrawal, A., "A Concept of Improving Strength of Concrete Using Human Hair as Fibre Reinforcement”, International Journal of Innovative Research in Science, Engineering and Technology, Volume 5, No. 5, pp. 8624-8629, 2016.

[8] Ansari, U.S., "Effect of Human Hair on Compressive Strength of Concrete", Shri Guru Gbbind Institute of Engineering \& Technology, Volume 22, 2016.

[9] Nila, V.M., Raijan, K.J., Antony, S., Riya, B.M., and Davis, N.R., "HairFibre Reinforced Concrete", International Journal of Research in Advent Technology, (E-ISSN: 2321-9637), Special Issue International Conference on Technological Advancements in Structures and Construction, Volume 32 10-11 June, 2015

[10] Ahmd, S., Ghani, F., and Hassan, M.,'Use of Waste Human Hair as Fibre Reinforcement in Concrete", Material Science and Engineering, Volume 71, 2015

[11] Katib, A. W., "Design and Performance of Sustainable/Green Concrete", M.Sc. Thesis, American University of Sharjah, Sharjah, UAE, 2015.

[12] Khansaheb, A.P., "Experimental Investigation on Properties of Concrete Using Human Hair andSugarcane Bagasse Ash”, International Journal of Innovative and Emerging Research in Engineering, Volume 32, No. 4, 2015. 
[13] Naveen, T.K., "Experimental Study on Mechanical Properties of Human Hair Fibre Reinforced Concrete", IOSR International Journal of Mechanical and Civil Engineering, Volume 12, No. 3,pp. 65-75, 2015.

[14] Tomas, U., and Ganiron, J., "Effects of Human Hair Additives in Compressive Strength of Asphalt Cement Mixture", International Journal of Advanced Science and Technology, Volume 67, No. 3, pp. 11-22,2014.
[15] Sameer, A., "Preparation of Eco-Friendly Natural Hair Fiber Reinforced Polymeric Composite(FRPC)Material by Using of Polypropylene and Fly Ash: A Review”, International Journal of Scientific \& Engineering Research, 2014.

[16] Batebi, Y., Mirzagoltabr, A., Shahanina, S.M., and Sara, F., "Experimental Investigation of Shrinkage of NanoHair Reinforced Concrete",IJEE An Official Peer Reviewed Journal of Babol Noshirvani University of Technology,Volume 2, pp. 68-72,2013. 